\title{
HOW STRATEGIC ARE STRATEGIC INFORMATION SYSTEMS? ${ }^{1}$
}

\author{
David Avison*, Alan Eardley** and Philip Powell\# \\ * Department of Management, University of Southampton, Southampton S017 1BJ, UK. \\ ** School of Computing, Staffordshire University Stafford, ST18 0AD, UK. \\ \# Information Systems Research Unit Warwick Business School, University of Warwick, Coventry CV4 7AL, UK.
}

Key words: Business strategy, competitive advantage, information technology, strategic information systems, strategy frameworks.

\begin{abstract}
There are many examples of information systems which are claimed to have created and sustained competitive advantage, allowed beneficial collaboration or simply ensured the continued survival of the organisations which used them. These systems are often referred to as being 'strategic'. This paper argues that many of the examples of strategic information systems as reported in the literature are not sufficiently critical in determining whether the systems meet the generallyaccepted definition of the term 'strategic' - that of achieving sustainable competitive advantage.

Eight of the information systems considered to be strategic are examined here from the standpoint of one widely-accepted 'competition' framework- Porter's model of industry competition. The framework is then used to question the linkage between the information systems and the mechanisms which are required for the enactment of strategic business objectives based on competition. Conclusions indicate that the systems are compatible with Porter's framework. Finally, some limitations of the framework are discussed and aspects of the systems which extend beyond the framework are highlighted.
\end{abstract}

\section{INTRODUCTION}

For almost as long as computers have been used in business, the strategic potential of automated information systems has been recognised. Kriebel (1968) and Whisler (1970) were among the first to identify the strategic importance of information systems and to discuss the necessary linkage between the information systems and a business framework. Systems which exhibit this linkage, and which enable companies to carry out specific business strategies, are termed 'strategic information systems' (Huff and Beattie 1985, Ciborra 1991, Krcmar and Lucas 1991). There are several contexts within which information systems have been said to play a strategic role, and a number of business frameworks have been invoked to describe the phenomenon of the strategic information system. This variety is less than helpful in defining the meaning of a strategic information system. Doyle (1991) considers the frameworks which have been used in this context to be diverse and allencompassing but that 'each may illuminate a particular aspect of the [system's] environment'. There has however, tended to be a consensus, with some notable exceptions (Huff and Beattie 1985), that strategic information systems are those systems which enable firms to achieve strategies of sustained competitive advantage over their rivals (Ciborra 1991, Krcmar and Lucas 1991). Some authors have attempted to draw a distinction between strategic and competitive' systems (Huff and Beattie 1985). The distinction centres upon the supposition that strategic systems help senior managers to create and monitor the strategic plan, whereas competitive systems help them to make the strategy operational. This view, while having merit, has tended not to garner the support of the academic or business communities. Therefore. the definition of strategic information system used here is an information system which is intended to enable its operator to achieve and sustain competitive advantage over its rivals under a variety of environmental conditions. This view is important to the choice of strategy framework for this study.

There is a considerable body of literature describing examples of information systems which have been instrumental in achieving business success for their operators. However, on examining these cases individually, it is often not clear to what extent the systems' success in achieving advantage is due to the features or attributes of the information system . In other words, is there something about these systems which has been crucial in enabling their operators to gain and to maintain an advantage over their rivals, or are the information systems in question simply a part of the overall resource portfolio of a successful company? This paper sets out to identify a suitable framework for describing a business strategy based on competition, and then applies that framework to a range of information systems which are said to be 'strategic', in order to assess whether the systems show features which match those of the framework. If this matching is evident, then it is reasonable to assume that the systems are 'strategic' in the sense of being instruments of competitive advantage. In short, it is

\footnotetext{
${ }^{1}$ An earlier version of this paper was presented at the 5th International Forum on Technology Management.
} 
the intention to examine the applicability of a widely-accepted competition framework to some of the frequently-reported examples of strategic information systems, using a comparison of the features of the framework with those of the systems to establish the match.

\section{THE FRAMEWORK}

As described, the intention here is to select a framework which may be used to define an information system as 'strategic' (rather than merely important or successful) and then apply the chosen framework to some of the 'classic' examples of strategic information systems. The choice of framework is clearly paramount. Of the available frameworks, Porter's model of competitive forces (Porter 1980) is cited most frequently in the literature (Boon 1988) and was developed initially as a tool for helping firms choose a strategy which is appropriate for a given market environment. The use of Porter's framework implies that the firm's management will seek to implement 'strategic moves' which seek to position the firm in its environment by balancing five environmental forces: competitors, customers, suppliers, substitute products and/or services and new entrants to the market or industry. The potential of these forces is to allow the firm to act in one or more of the following ways:

- To change the basis of competition among rivals;

- To reduce the bargaining power of suppliers;

- To reduce the mobility of customers in seeking alternative suppliers;

- To prevent the introduction to the market of substitute products or services;

- To manipulate entry to the market by creating or demolishing barriers to entry.

These strategic moves may be carried out within the context of three generic business strategies:

- Establishing cost leadership as a way of acquiring market share;

- Differentiating its products or services from those of its rivals;

- Focussing on one particular market niche or sector.

In the context of strategy development, the strategy serves the long-term aims which the organisation has, the strategic moves or 'thrusts' are options which will take the organisation in the chosen direction, and the moves are implemented by 'mechanisms' which are directed at a particular target (Wiseman 1985). Porter's framework, as extended by others (Porter and Millar 1985, Cash and Konsynski 1985, McFarlan 1984), suggests and identifies IT-based mechanisms by which the objectives of the strategy may be implemented. Earl (1989) summarises this work and suggests two further uses for the framework: in identifying strategic applications of information technology; and for testing ideas for gaining competitive advantage against predetermined business objectives. Earl's explanation of the uses of Porter's framework in line with the work of other authors, is depicted in Table 1.

Table 1. Porter's framework in use (after Earl 1989)

Force

1. Competition among rivals

2. Mobility of customers

3. Supplier bargaining

4. Substitute products or services

5. New entrants to market
Potential

Change basis of competition collaborate

Lock-in to firm

Reduce bargaining

Innovate

existing product

Create barriers to entry own
Mechanism

Compete or

Differentiate or

create switch costs

Erode or share power

Develop new product or add value to

Demolish or erect

A review of the literature shows the impact which Porter's framework has had on research in the link between business and information technology. An early application of Porter's framework by Parsons (1983) assessed the strategic importance of IT applications and Cash and Konsynski (1985) use the same framework to evaluate the strategic importance of inter-organisational information systems. The framework also forms a basis for work which explores the links between corporate strategy and IT (Bacos and Treacy 1986) and an examination 
of the strategic risks to information systems development (Vitale 1986). Porter's framework is a 'convenient and useful tool for communicating the potential of IT to managers and practitioners' (Boon 1988).

Porter's model is termed 'the most fundamental of these (frameworks)' in an empirical study into the strategic uses of information and information technology (King, Hufnagel and Grover 1988). It is also a useful benchmark against which to evaluate the success of strategic information systems as the theory on which the framework is based are grounded in the business and cultural environment within which most of the 'classic' strategic systems were developed. Ciborra (1994) sees drawbacks to the use of Porter's framework in an examination of four strategic information systems cases (three of which are re-examined here). He emphasises the discepancy between a well-defined approach to developing strategic information systems (such as would be achieved with a framework) and the realities which often include chance, serendipity, trial and error, and gross negligence, suggesting that successful competitive systems need to emphasise the creation of value, and that such systems should be rare and difficult to imitate. He concludes, 'the question is, then, how to achieve rarity and imperfect imitability in designing a SIS [strategic information system]? The analysis of the competitive environment as prescribed by Porter (1980) is lacking in this respect' (Ciborra 1994 p.15).

\section{THE METHODOLOGY}

A large body of rather unstructured material exists which describes individual instances of strategic information systems. A search of the relevant journals and the index of the Harvard Business School Case Service reveals twenty such systems which are specifically described in terms of their strategic success. For the puposes of this study a set of criteria was devised to screen these candidate cases, the criteria are intended to clarify the issues and to ensure compatibility between the chosen cases, rather than to test compliance with Porter's framework. Cases which did not meet the following criteria are excluded:

- There must be a means of comparing one case with another. In practice at least two cases from each of a number of business sectors are included;

- There must be a description of the background or business context within which the system was developed;

- The combined references have to describe the examples in sufficient detail to allow a reasonable level of understanding of the systems;

- The information systems must have been developed in the first instance by a single entity, as opposed to a collaborative venture.

After the screening process there remain eight well-documented cases which can be placed into three business sector classifications. These are presented in Table 2. A secondary role of this paper is to re-evaluate some of these cases, which have often been the subject of 'secondary analysis', and to take the opportunity is taken to go back to the primary sources to assess whether the claims made for these systems are justified.

A number of issues emerge when the literature on strategic information systems is examined:

- A small number of examples of strategic information systems constitutes the majority of the published cases. These cases have been described frequently and used as exemplars, often going on to become regarded as 'classic' in their field. This may have affected the reviewed sample, as other cases which may be equally deserving of analysis are not sufficiently well-reported to meet the inclusion criteria;

- Many of the references to the systems are anecdotal and few would claim to be original studies. There is a shortage of comparative or analytical work and few publications seek to justify formally the claims of strategic importance which have been made on their behalf. Exceptions to this are Boon's (1988) research into 14 cases of strategic information systems and the empirical study by King, Hufnagel and Grover (1988) of 84 companies which claimed to have developed such systems;

- Most of the published cases (and all those which meet the inclusion criteria of the present study) are from the USA, and the majority of the systems were developed progressively over more than twenty years, from the late 1960 s to the early 1990 s. 
Table 2. Strategic Information Systems Cases

\begin{tabular}{lll}
$\begin{array}{l}\text { Sector/Company } \\
\text { Airlines }\end{array}$ & System & Type \\
\hline $\begin{array}{l}\text { American Airlines } \\
\text { United Airlines }\end{array}$ & SABRE & Reservation/booking \\
$\begin{array}{l}\text { Distribution } \\
\text { Baxters (AHS) }\end{array}$ & Apollo & Reservation/booking \\
$\begin{array}{l}\text { Federal Express } \\
\text { McKesson }\end{array}$ & ASAP & Order/stock control \\
Financial Services & COSMOS & $\begin{array}{l}\text { Consignment/routeing } \\
\text { Order/stock control }\end{array}$ \\
$\begin{array}{l}\text { Meritil Lynch } \\
\text { Philadelphia Nat. Bank }\end{array}$ & Economost & Ording \\
& GTN & Global trading \\
& CMA & Integrated cash a/c. \\
\end{tabular}

The methodology of the review is to examine the cases and the framework in two ways. First, the systems are categorised and analysed to determine if a correlation exists between their features as described in the cases and Porter's framework, in order to test the validity of the claim that the systems have strategic dimensions. Second, the results of the analysis are used to evaluate Porter's framework as a valid instrument for the identification and definition of strategic information systems.

\section{CASE ANALYSIS}

One problem apparent in the study is to match the method of analysis to the degree of detail available in the published data. One study of strategic systems uses economic analysis techniques to examine the deployment of information technology and the levels of customer switching cost which would be involved in reponding to some of the forces (Barua, Kriebel and Mukhopadhyay 1991), but this is at an aggregated industry level, and no such data is available for the individual cases. In the end, it was decided to use a form of feature analysis (Law 1988) to match the published features of the chosen systems with those of Porter's framework. This involved searching the literature for evidence of information systems-based mechanisms which the firms had put into place to exploit or to counter the potential strategic moves suggested by Porter's model and to record the evidence in narrative form. Although it is not possible to reproduce the richness of data which is present in the published cases, the findings on each of the five forces are briefly as follows, and are reinforced in Table 3:

\section{Competition Between Rivals}

It is apparent that the key to success in this area is to use IS to change the basis of competition in an industry. The systems which were the most successful at changing the basis of competition were those which had 'first mover' or 'early adopter' status and achieved an early technological advantage. Of the eight cases examined, five had changed the basis of competition in their respective industries. The exceptions were United Airlines and Philadelphia National Bank (PNB), both of which entered systems into a sector which had already seen the effects of systems introduced by rivals. In such cases a competitive struggle ensued which only resolved itself when a state of stability was reached, in the former case by gaining control of the booking channels and in the latter case by assimilating many of the competing ATM systems.

In the case of the SABRE and Apollo systems the two systems were in direct competition since potential passengers preferred to fly on whichever airline could offer them the first booking. SABRE was, however, the pioneering system in the airline industry and was the first to gain widespread acceptance with travel agents when the agents and the airline companies failed to agree on a joint nationwide reservation system (Emery 1990). American Airlines had its system in an advanced stage of development and was therefore able to control the booking channels of a large part of the U.S. air travel industry. It soon began processing reservations for its competitors for a fee, which came to be an important new form of revenue, amounting to almost $50 \%$ of profits in 1991 (Senn 1992).

The American Hospital Supply (later Baxter's) ASAP (later called ASAP Express) and McKessons' Economost systems have similar functionality, but were operating in different markets (hospitals and pharmacies). Both companies were therefore able to revolutionise the way in which orders were placed in their respective sectors, and both systems were judged to be strategic successes. Federal Express Corporation gained a first-mover advantage by effectively creating a new industry - the overnight package delivery service (Senn 1992) through the use of its COSMOS parcel routing and tracking system. The advantage was soon wiped out, however, as a 
number of companies sought to exploit the new overnight market by developing competing systems. These 'follower' companies, which included United Parcels Service, Airborne Freight Corporation and Emery Air Freight, had the advantage of being able to observe the functioning of the COSMOS system and to take advantage of more recent technological developments. Federal Express, therefore, did not find that changing the basis of competition by using a strategic information system has given it the degree of long-term advantage which might have been expected, and it had borne the research and development costs for the entire industry in return for a temporary competitive advantage.

Three things are apparent from this scenario; first, that it is particularly important for 'first-movers' to gain the maximum benefit from their systems as soon as is possible, and second, that the initial competitive advantage may be at best temporary unless very unusual circumstances apply. Third, any move involving strategic applications of IS may, unless defended well, invoke a superior response from competitors. Dos Santos and Peffers (1991) concur with this view in their analysis of IT adoption by US banks in which they find that smaller banks and banks with a slow rate of growth were not able to make gains from the early adoption of IT, while other banks found the advantage to be temporary (particularly in terms of market share) although some long-term gains were made in terms of efficiency.

\section{Customer Mobility}

Several of the systems show clearly attempts to achieve control of the firms' supply chains. In particular, the two airline booking systems and the AHS and McKesson systems show evidence of mechanisms designed to 'lock-in' customers by opening a channel which differentiated their service from that of their competitors. This created switching costs if the customer sought to exercise mobility by dealing with competitors. In return it has been claimed that the benefits which resulted from the use of the system were passed on to the customer (Clemons and Row 1988). Merrill Lynch's Cash Management Account (CMA) system offered a complete range of financial services to individual customers for the first time, based upon the use of a computerised personal account. The range of features which the system offered was intended to make it unnecessary for the bank's customers to use competitors' services. The customer would also incur switching costs in the event of a change of service provider, as most of the competing financial products carried a front-end charge. American Airlines was also able to lock-in customers in two ways, both of which made possible by SABRE. First, there was the securing of the channels of services which locked-in travel agents by providing a dedicated IT system at the agents' premises and second, this was achieved by using the system as the basis for running the American Advantage frequent flier programme, which created a club of over 11 million regular users who were 'rewarded' for not using the services of competitors (Hopper 1990).

\section{Bargaining Power of Suppliers}

There is little direct evidence that any of the chosen systems were developed with a strategy in mind of reducing supplier bargaining power, although Laudon and Laudon (1988) cite the examples of SABRE and Apollo as examples of strategic information systems which have such an affect upon suppliers. They state, 'for instance, United has begun to include in its contracts with travel agents provisions that prevent them from using any other airlines (sic) system if they want to keep Apollo. This is an example of how a strategically oriented supply system gives a supplier a market advantage over a distributor and a customer'. Similarly, the ASAP system could also be considered to affect supplier relationships. Cash et al. (1992) quote the president of Baxter's Hospital Systems Division, 'ASAP Express opens up a new era of electronic order entry in which suppliers must compete in other areas such as product line breadth, distribution capabilities, and value-added services' (p.162). ASAP Express therefore promotes not only the sales of Baxter's products but also those of its suppliers. Baxter's also initiated 'VIP' - a system which linked the firm to its suppliers. This was a later system and it may be that the mechanisms for making such a strategy operational did not exist at the time the systems were originally initiated and so do not 'show up' in the case studies.

\section{Substitute Products and Services}

Several of the organisations described in the cases appear to have used a strategy of incremental development and improvement of their systems as a counter to the threat of competitors entering the market with new products or services. Two strategies can be applied by a firm to counter this force. First, the firm which is being attacked may try to introduce a new strategic information system with which it hopes to restore the state of competitive advantage which it previously enjoyed, and second, the firm may seek to develop an existing 
system to give it extra functionality with which it may outperform its rivals. A third strategy, which is less well researched, is to create illusory barriers to entry by undertaking visible high spending on IT (Powell 1992).

It is interesting to compare the way in which two of the companies had to cope with the force of competition from the substitute services of rivals. Federal Express and Merrill Lynch are almost at opposite ends of the spectrum in terms of the need to stay one step ahead of the competition. Merrill Lynch's CMA was a radically new financial service (developed from ideas put forward by the Stanford Research Institute) which enabled the firm to capture $90 \%$ of the market for investment account products in the first year of operation. Perhaps because of its initial success, the system was not enhanced for several years and when systems were developed by competitors which offered similar facilities in different ways its share of the market dropped to $50 \%$ (Boon 1988).

In contrast, the American Airlines' SABRE system and Federal Express Corporation's COSMOS show distinct evidence of 'value adding' developments being made as a direct response to innovations made by the competition in order to stay one step ahead. Some of the improvements Federal Express made to the original COSMOS system include organisational enhancements (e.g. a hub-and-spoke distribution complex), operational features (e.g. on-line parcel tracking and direct aircraft assignment) and technological developments (e.g. display units in truck cabs). These competitive developments allowed the firm to avoid competing on price alone and have been 'instrumental in allowing it to maintain its position in the market' (Senn 1992, p.10).

\section{New Entrants to the Industry}

Proponents of Porter's framework suggest that there are three main reasons why a first-mover's development of a strategic information system should act as an effective barrier to prevent rival firms from entering a given industry or market sector:

- Information systems of the scale that is necessary to achieve anindustry-wide strategic effect are bound to have long planning and development times. This alone should guarantee a considerable period of freedom from competition;

- The development of such systems is extremely costly in terms of risk, finance and human resources, so that only firms with a large resource base are able to produce them;

- The technical and organisational expertise which is needed to produce this type of system is in short supply.

In fact, experience shows that these barriers can be illusory or at most temporary. Time and cost factors are constantly being reduced by methodological and technological developments and the supposed monopoly of technical expertise has been broken (if it ever existed) by the fluidity of the IT labour market and the prevalence of consultancy services. Therefore, the evidence from the cases to confirm or deny the effectiveness of information systems as barriers to entry is inconclusive. One of the criteria for including the cases in this study is that there should be at least two examples in each business sector - all the companies, therefore, have competitors, suggesting that the systems may have reduced the number of entrants or have delayed entry but have not been effective in preventing it completely. There is more evidence of the success of information systems at demolishing barriers than at erecting them. Several of the cases describe a company which has been able to enter a market by using information technology as a substitute for some other factor: 'High Street' bank branches in the case of Merrill Lynch and a distributed sales operation in the case of American Hospital Supply.

Companies have chosen to collaborate in the development of strategic information systems for a variety of reasons. Merrill Lynch, for instance, had to collaborate with Banc One in order to provide the current account and credit facilities for its CMA system, as existing U.S. legislation did not allow an investment bank to offer such services. It is interesting to note that, in view of Merrill Lynch's long dominance of the market, this collaboration appeared to have no effect on other firms entering the market, as Banc One subsequently acted as a partner to several of Merrill Lynch's competitors of in a number of ventures. Nevertheless, the combination of Merrill Lynch's investment expertise and Banc One's technological innovation went almost unopposed in their market sector for five years. Philadelphia National Bank used collaboration as a way of enabling its shared ATM system 'MAC' to overcome the effects of scale and first-mover advantages which were enjoyed initially by Girard (later named Mellon Bank) in the Philadelphia area with its 'George' ATM system. PNB maintained ownership of the network as a service provider and was able to attract enough banks into its MAC network for the system to overtake George (by then called Cashstream) and PNB was eventually able to absorb Cashstream into its own system when it took over part of Mellon Bank's operations (Clemons 1990). 


\section{DISCUSSION}

By comparing Porter's framework with the details of the cases it is possible to draw general conclusions about the framework which cast light upon the nature of strategic information systems. The findings indicate that the strategic information systems described provide a partial match with Porter's framework in that they define strategic moves, identify strategic potential and suggest mechanisms in relation to some, but not all, of the forces of the model. The results are summarised in Table 3 and are described below:

- Six of the eight cases show evidence of the characteristic strategy which Porter terms 'changing the basis of competition'. All the systems have been cited as the direct cause of the relative success of the companies which operated them. In the case of direct competition between companies for a defined market (for instance American Airlines and United Airlines) it is apparent that one of the companies has achieved a measure of competitive advantage over the other. In the cases of collaboration between companies (for instance PNB and Merrill Lynch) the degree of success is more difficult to define, although it is notable that CMA was pre-eminent in its market for five years and MAC did absorb most of the rival ATM systems in the Pittsburg area.

Table 3. Summary of Strategic Moves in Response to Forces

\begin{tabular}{|c|c|c|c|c|c|c|}
\hline \multirow[b]{2}{*}{ Company } & \multicolumn{6}{|c|}{ Forces in Framework } \\
\hline & System & $\begin{array}{l}1 \\
\operatorname{Res}\end{array}$ & $\begin{array}{c}2 \\
\text { se Mechan }\end{array}$ & 3 & 4 & 5 \\
\hline $\begin{array}{l}\text { American } \\
\text { Airlines }\end{array}$ & SABRE & $\begin{array}{l}\text { change } \\
\text { basis }\end{array}$ & incentive & & $\begin{array}{l}\text { added } \\
\text { value }\end{array}$ & \\
\hline Apollo & & & switching & & & \\
\hline Airlines & & & costs & & & \\
\hline $\begin{array}{l}\text { Baxters } \\
\text { AHS }\end{array}$ & ASAP & $\begin{array}{l}\text { change } \\
\text { basis }\end{array}$ & $\begin{array}{l}\text { switching } \\
\text { costs }\end{array}$ & & & erect \\
\hline $\begin{array}{l}\text { Federal } \\
\text { Express }\end{array}$ & COSMOS & $\begin{array}{l}\text { change } \\
\text { basis }\end{array}$ & & & $\begin{array}{l}\text { added } \\
\text { value }\end{array}$ & demolish \\
\hline McKesson & Economost & $\begin{array}{l}\text { change } \\
\text { basis }\end{array}$ & $\begin{array}{l}\text { switching } \\
\text { costs }\end{array}$ & & & \\
\hline Citicorp & GTN & & $\begin{array}{l}\text { switching } \\
\text { costs }\end{array}$ & & & \\
\hline $\begin{array}{l}\text { Merrill } \\
\text { Lynch }\end{array}$ & CMA & $\begin{array}{l}\text { change } \\
\text { basis }\end{array}$ & $\begin{array}{l}\text { range of } \\
\text { services }\end{array}$ & & & erect \\
\hline PNB & MAC & $\begin{array}{l}\text { change } \\
\text { basis }\end{array}$ & & & & demolish \\
\hline
\end{tabular}

Key to forces: 1. Competition among rivals 4 4. Substitute products or services

2. Mobility of customers 5 . New entrants to the market

3. Supplier bargaining power

- Six of the cases exhibit signs of the strategy of reducing customer mobility by an apparent attempt to lock-in customers (as opposed to an increase in market share through competitive pressure). Attempts were made to exercise such power over the customer in several ways; American Hospital Supply and McKesson used the strategy of sharing the technology with the customer to create switching costs should the customer seek to develop an in-house equivalent of the system. American Airways secured the loyalty of air travellers by using SABRE to log their flights and to provide a frequent flier bonus as an incentive and Merrill Lynch used the range of financial services which are offered by CMA to make it unnecessary for customers to open specialised accounts with competitors.

- None of the cases exhibit the related strategy of responding to suppliers' bargaining power by sharing or eroding that power. This may be due to the size of the sample or to some characteristic of the sample, such as the era in which the systems were developed. There are a number of instances of this feature being displayed by strategic information systems (e.g. Stalk 1988, Gooding 1988). 
- As the literature about the cases fails to describe the market situation which existed before the development of the systems, it is impossible to assess how many of the systems were part of a strategy of response to competitive products or services. Neither is it clear how many firms had tried to introduce competitive systems and failed, since these cases go unreported. There is direct evidence that the management of the companies which operated four out of the eight systems made value adding enhancements to the systems' functions in order to stave off the threat of substitution. It is clear that these enhancements are strategic moves, independent of any technology-led improvements which may have been made to the systems.

- There is evidence that four out of the eight cases had responded to the force relating to market entry. Two of the cases show evidence of the use of the system to create a barrier to other companies entering the market. In these cases the barrier is related to the scale of the system and to the first mover effect rather than the difficulty of development. In fact, few of the systems used more sophisticated technology than the average transaction processing system of the relevant era. The proportion of systems which exhibit this characteristic is less than might be expected. Two of the cases (Federal Express and PNB) show clear evidence of the use of systems to demolish barriers which had been erected by competitors with first-mover advantage. PNB applied the classic strategy of barrier demolition by using a shared ATM system to enter the market and to gain market share. The cases of American Airlines and Citicorp (with its GTN system) also exhibit this characteristic quite strongly.

It is clear from the above that the majority of the systems included in the survey map onto Porter's framework to an extent which goes beyond coincidence. It is immediately apparent that there is a disparity in the number of forces to which the companies have responded. All the cases presented in the previous sections exhibit evidence of compliance with at least one dimension of the framework, and three of the eight comply with three dimensions. The most common factor which influenced the firms' strategic moves is the force of competition from rivals. The systems in seven of the eight cases had mechanisms which addressed this. The only force which was possibly not present in the systems was that of seeking to control the bargaining power of suppliers. Of course, it could be argued that Porter's framework has been derived from practice. Indeed, perhaps derived from analysis of some of the cases analysed here. Hence, a good mapping between the framework and reality would be expected.

It may be tempting to construe from these findings that the systems which best fit the framework are more strategic or more successful. Certainly in the cases where a direct comparison within a business sector between a high-scoring and a low-scoring system is possible (for instance American Airlines and United Airlines), the company in the former category has been more successful in several important business areas.

\section{LIMITATIONS IN APPLYING THE FRAMEWORK}

One view is that since the systems in the review comply strongly with some of the competitive forces with Porter's model (i.e. those relating to rivals and to customers), and since the model is widely accepted as a strategy framework, then by definition these systems must have a significant strategic value to their operators. However, there are other aspects of the systems in the cases which are not covered by Porter's framework but which are worth examining in relation to their strategic or competitive potential:

- It is possible to confuse the concept of 'strategic' with 'important' or 'pervasive' when discussing information systems. All the cases describe large, complex systems which reach into many areas of the businesses that use them. There is no doubt that some parts of these systems impart a strategic advantage to the firms, but to state that the information system as a whole is strategic or 'competitive' would seem to go against common sense. It may, therefore, be more accurate to state that the majority of the systems in these cases are information systems with strategic dimensions or strategic components. To do otherwise would confuse importance to the business with 'strategic value', a fault which one author has called 'a mischievous misconception' (Emery 1990);

- It may be possible to refer to any system in a successful, competitive firm as 'strategic'. Just as it is possible to confuse the terms 'strategic' and 'important' when referring to information systems, so it is easy to refer to an information system as 'strategic' when what is meant is 'successful'. A review of the literature finds few descriptions of strategic information systems which are failures (at least in the short term). Exceptions are the case of Olin Chemical Group (Senn 1992) and 'Winchester Tyres'. It may be pointed out that the firms which operate some of the notable strategic systems already dominated their respective markets before the systems were developed. However, in the 
cases from the distribution sector under study here (ASAP, Economost, and COSMOS), the applications (and in the case of COSMOS, the industry) simply could not have existed without the information systems to drive them;

- It may be said that a system can only be strategic if it is an indigenous part of an organisation's long-term strategy, and many of the examples in the study do not appear to have been planned from their inception, but were developed in an evolutionary manner (Ciborra 1994, Krcmar and Lucas 1991). The example which best illustrates this is American Airlines' SABRE, which was conceived in 1959 as an internal data processing system. Relatively few of the enhancements which were to give the system its strategic value to the company over the next 16 years appear to have been planned in any long-term way, but were developed as a result of piecemeal enhancements in response to changes in the air travel market such as the breakdown of negotiations for a shared system and deregulation of the industry. In the case of Economost, McKesson's former IS manager admits that the system owes its development not to a top-level, company-wide strategic plan but to a local initiative by one of its business units (Clemons and Row 1988). This in no way diminishes the strategic impact which the systems had upon the organisations and Porter's framework models this dynamic with the concepts of 'strategic moves' in response to one or more of the forces.

- It could be argued that Porter's framework does not describe one of the most important aspects of a strategic information system, that of providing information from which strategic plans may be formed and upon which strategic decisions may be based, which is one definition of a strategic information system (Fredericks and Venkatraman 1988),. All the systems have reporting and interrogation facilities but in most cases these can only be seen as improving the efficiency of that system (for instance, ASAP allows for the optimisation of stock and re-order levels). There is no evidence that any of the systems provide the sort of information which would enable top-level management to identify, for instance, the sort of opportunities and threats to which the companies respond in formulating strategies. SABRE has a facility which monitors competitors' fares and optimises its own ticket prices to maximise revenue, but this could hardly be called strategic, although it may help American Airlines to be more competitive.

\section{CONCLUSIONS}

The information systems described in these cases show a significant degree of compliance with at least part of Porter's framework. This framework is one of the most commonly accepted models for describing the strategic actions of companies in an industry. The dynamic of tension, response and balance which this model implies is echoed in the incremental way in which most of these systems described in the cases have been developed over time. However, there are other perspectives by which the strategic nature of such information systems may be judged. One view is that the nature of an information system (in terms of scale, success and importance to the business) is often confused with strategic worth. Another is that the cases are in some way tied in to the use of the framework, and that the definition of strategic value which is attributed to the systems is rooted in the common cultural and temporal background which gave rise to both the framework and the systems. The business-driven need to gain a strategic advantage from the use of information technology and to justify the development of such systems may have led to claims that the systems are strategic in nature.

There is clear evidence from the cases of the use of information systems as mechanisms to exploit and to secure business opportunities. There is, however, an obvious problem in the use of Porter's framework in this study, which is related to the definition of the term 'sustainable', as the cases show that competitive advantage is rarely sustained without changes being made to the information systems which are intended to achieve it (Senn 1992, Ciborra 1991). In fact, this should not detract from the strategic value of the systems in the study, or from the relevance of Porter's framework, as the model describes adequately the need for continual change in response to a dynamic environment. Strategies such as 'locking-in' customers and changing the basis of competition in a market sector can be effective over a prolonged time period, providing that continuous improvements are made to the strategy and to the mechanisms which are in place to enact it. Porter's framework can provide a valuable tool for scanning the environment and for prompting such changes to reestablish competitive advantage by the use of information systems.

\section{REFERENCES}

Bacos, J.Y. \& Treacy M.E., (1986), I.T. and Corporate Strategy: A Research Perspective, MIS Quarterly, 10(2), pp.106-119. 
Barua, A., Kriebel, C.H. \& Mukhopadhyay, T. (1991), An Economic Analysis Of Strategic Information Technology Investments, MIS Quarterly, September, pp.313-331.

Boon, S.N., (1988), Factors Facilitating The Use Of Information Technology For Competitive Advantage: An Exploratory Study, Information and Management, (15), pp.191-201.

Cash, J.I. \& Konsynski, B.R., (1985), I..S. Redraws Competitive Boundaries, Harvard Business Review, 63(2), pp.134-142.

Cash J., McFarlan W., McKenney \& Applegate L., (1992), Corporate Information Systems: Text and Cases, New York, Irwin.

Ciborra, C, (1991), The Limits Of Strategic Information Systems, International Journal of Information Resource Management, 2(3), pp.11-17.

Ciborra C., (1994), The Grassroots of I.T. and Strategy, in Ciborra C. and Jelassi T., Strategic Information Systems; A European Perspective, Chichester, Wiley, pp.3-24.

Clemons, E.K. \& Row, M., (1988), McKesson Drug Company: A Case-Study of Economost - A Strategic Information System, Journal of Management Information Systems, 5(1), pp.37-50.

Clemons, E.K., (1990), MAC-Philadelphia National Bank's Strategic Venture In Shared ATM Networks, Journal of Management Information Systems, 7(1), pp.5-25.

Dos Santos, B. \& Peffers, K., (1991), The Effects Of Early Adoption Of IT: An Empirical Study, Proceedings of 12th. Annual Conference on Information Systems, New York, pp.127-140.

Doyle, J., (1991), Problems with Strategic Information Systems Frameworks, European Journal of Information Systems, 1(4), Dec., pp.273-280.

Earl, M.J., (1989), Management Strategies for I.T., London, Prentice Hall International.

Emery, J.C., (1990), Misconceptions About Strategic Information Systems: Editor's Comments, MIS Quarterly, June, pp. vii-viii.

Fredericks, P. \& Venkatraman, N. (1988), The Rise of Strategy Support Systems. Sloan Management Review, 29 (3) pp. 47-54.

Gooding, G., (1988), Exploiting I.T. in Business Development: Ford in Europe, in M.J. Earl (Ed.), Information Management: The Strategic Dimension., Oxford, Oxford University Press, pp.87-97.

Hopper, M., (1990), Rattling SABRE: New Ways To Compete On Information, Harvard Business Review, 68(3), pp. 118-125.

Huff, H.L. \& Beattie, E.S., (1985), Strategic Versus Competitive Information Systems, Business Quarterly, 50(4), pp.97-102.

King, W., Hufnagel, E. \& Grover, V., (1988), Using Information Technology For Competitive Advantage, In M.J. Earl (Ed.), Information Management: The Strategic Dimension, Oxford, Oxford University Press, pp.87-97.

Krcmar, H. \& Lucas, H.C., (1991), Success Factors For Strategic Information Systems, Information and Management, 21(3), pp.137-145.

Kriebel, C.H., (1968), The Strategic Dimension Of Corporate Systems Planning, Long Range Planning, pp. 812.

Law, D., (1988), Methods For Comparing Methods, Manchester, N.C.C.

Laudon K. \& Laudon J., (1988), Management Information Systems. New York, Macmillan.

Mcfarlan, F.W., (1984), IT Changes The Way You Compete, Harvard Business Review, 62(3), pp.98-

113.

Parsons, G., (1983), IT: A New Competitive Weapon, Sloan Management Review, 25(1), pp.3-14.

Porter, M.E., (1980), Competitive Strategy, New York, Free Press.

Porter, M.E. \& Millar, V.E., (1985), How Information Gives You Competitive Advantage, Harvard Business Review, July-Aug, pp. 140-160.

Powell, P., (1992), Information Technology Evaluation: Is It Different? Journal of The Operations Research Society, 43(1), pp.29-42.

Scott Morton M., (1992), Reshaping the Corporation of the Future, Revue des Systemes de Decision, 1(2-3), pp. $121-126$.

Senn, J.A., (1992), The Myths Of Strategic Systems; What Defines Competitive Advantage, Information Systems Management, 9(3), pp.7-12.

Stalk, G., (1988), Time - The Next Source Of Competitive Advantage, Harvard Business Review, July- Aug, pp.41-51.

Vitale, M.R., (1986), The Growing Risks of IS Success, MIS Quarterly, 10(4), pp.327-334.

Whisler, T., (1970), Information Technology And Organisational Change, New York, Wadsworth.

Wiseman, C., (1985), Strategy And Computers, New York, Dow Jones Irwin. 